\title{
AUTHOR INDEX FOR VOLUME 94
}

AHMADI, K. and SAZEEDEH, R.; Hereditary torsion theories of a locally noetherian Grothendieck category

ALAVI, S. H., DANESHKHAH, A. and JAFARI, A.; Groups with the same character degrees as sporadic almost simple groups

ALHARBI, A. O. M.; The biological treatment of wastewater: mathematical models

ALLAHYARI, R., ARAB, R. and HAGHIGHI, A. S.; Measures of noncompactness in a Sobolev space and integro-differential equations

497

ANDRUSZKIEWICZ, R. R. and WORONOWICZ, M.; A torsion-free abelian group exists whose quotient group modulo the square subgroup is not a nilgroup

ARAB, R.; see ALLAHYARI, R.

BAČA, M., MILLER, M., RYAN, J. and SEMANIČOVÁ-FEŇOVČÍKOVÁ, A.; On $H$-antimagicness of disconnected graphs

BAILES, J. S.; Orbispaces, configurations and quasi-fibrations

BARMAN, R., RAHMAN, H. and SAIKIA, N.; Counting points on Dwork hypersurfaces and $p$-adic hypergeometric functions

BAXTER, L. H., LYONS, J. W. and NEUGEBAUER, J. T.; Differentiating solutions of a boundary value problem on a time scale

208

BELTRÁN, A., FELIPE, M. J. and MELCHOR, C.; Normal subgroups whose conjugacy class graph has diameter three

101

BLIZNAC, M. and FILIPIN, A.; An upper bound for the number of Diophantine quintuples

BOURNE, C.; Topological states of matter and noncommutative geometry

BOURQUI, D. and SEBAG, J.; Deformations of differential arcs

BUCKLEY, M.; Three studies in higher category theory: fibrations, skewmonoidal structures and excision of extremals

CAIRNS, G., MENDAN, S. and NIKOLAYEVSKY, Y.; A sufficient condition for a pair of sequences to be bipartite graphic

CAVENAGH, N. J. and WANLESS, I. M.; There are asymptotically the same number of Latin squares of each parity

CHEN, T.; see LIU, F.

CHEN, Y., HU, X., LUO, Y. and SAPIR, O.; The finite basis problem for the monoid of two-by-two upper triangular tropical matrices

266

384

349

405

337

195

187

CHOI, Y.; Triviality of the generalised Lau product associated to a Banach algebra homomorphism

CHUNG, J.; General stability of the exponential and Lobačevskiir functional equations

DANESHKHAH, A.; see ALAVI, S. H.

DE ANDRADE, A. F. and SHUMYATSKY, P.; Bounding the order of the nilpotent residual of a finite group 
DE LUCA, A. V. and DI GRAZIA, G.; Groups of infinite rank with normality conditions on subgroups with small normal closure

DI GRAZIA, G.; see DE LUCA, A. V.

DICKINSON, J.; Development of a process model for the prediction of absorbent degradation during $\mathrm{CO}_{2}$ capture

DISSANAYAKE, G. S.; Advancement of fractionally differenced Gegenbauer processes with long memory

DONG, X. D. A.; Bayesian analysis of reserving models and applications

DU, X.; see LIU, R.

EBRAHIMI VISHKI, H. R.; see FAAL, R.

ELSHOLTZ, C.; Almost all primes have a multiple of small Hamming weight

FAAL, R. and EBRAHIMI VISHKI, H. R.; More on the Arens regularity of $B(X)$

FELIPE, M. J.; see BELTRÁN, A.

FILIPIN, A.; see BLIZNAC, M.

GABRIYELYAN, S. S. and MORRIS, S. A.; An open mapping theorem

GONZÁLEZ, A. and LÓPEZ-LÓPEZ, J. L.; Compactness of spaces of convex and simple quadrilaterals

HAGHIGHI, A. S.; see ALLAHYARI, R.

HAJDU, L., LAISHRAM, S. and SZIKSZAI, M.; Perfect powers in products of terms of elliptic divisibility sequences

HARE, K. E. and HE, J.; Smoothness of convolution products of orbital measures on rank one compact symmetric spaces

HE, J.; see HARE, K. E.

HEYMAN, R.; Topics in divisibility: pairwise coprimality, the gcd of shifted sets and polynomial irreducibility

HIRANO, M., KATATA, K. and YAMASAKI, Y.; Ramanujan Cayley graphs of Frobenius groups

HORBACZEWSKA, G. and LINDNER, S.; Resolvability of measurable spaces HU, X.; see CHEN, Y.

HUANG, Z. H.; see PAN, J. M.

HUH, J. and LIM, E.; Refinements of the first and second positive crank moments

JAFARI, A.; see ALAVI, S. H.

JALEEL, A. A.; Constructing free resolutions of cohomology algebras

JIA, H.; see LIU, R.

JONES, P. R.; A note on the Howson property in inverse semigroups

KALA, V.; Universal quadratic forms and elements of small norm in real quadratic fields

KATATA, K.; see HIRANO, M.

LAISHRAM, S.; see HAJDU, L.

LI, C., YI, X. and QIAO, S.; A note on the $p$-supersolubility of finite groups 
LIN, L. and ZHANG, Y.; The strong irreducibility of a class of Cowen-Douglas operators on Banach spaces

LINDNER, S.; see HORBACZEWSKA, G.

LIU, F., CHEN, T. and WU, H.; A note on the endpoint regularity of the HardyLittlewood maximal functions

LIU, R., DU, X. and JIA, H.; Wiener index on traceable and Hamiltonian graphs 362

LIU, Y.; see LIU, Y. J.

LIU, Y. J. and LIU, Y.; A character-theoretic criterion for the solvability of finite groups

LÓPEZ-LÓPEZ, J. L.; see GONZÁLEZ, A.

LUO, Y.; see CHEN, Y.

LYONS, J. W.; see BAXTER, L. H.

MA, S.-M. and WANG, H.-N.; Enumeration of a dual set of Stirling permutations by their alternating runs

MAGALINGAM, P.; Complex network tools to enable identification of a criminal community

MARQUES, D. and RAMIREZ, J.; On exceptional sets: the solution of a problem posed by K. Mahler

MELCHOR, C.; see BELTRÁN, A.

MENDAN, S.; see CAIRNS, G.

MICHALSKA, M. and MICHALSKI, A. M.; A generalisation of the ClunieSheil-Small theorem

MICHALSKI, A. M.; see MICHALSKA, M.

MILLER, M.; see BAČA, M.

201

MOLNÁR, L.; The logarithmic function and trace zero elements in finite von Neumann factors

MORRIS, S. A.; see GABRIYELYAN, S. S.

NAHEED, A.; A study of spatio-temporal spread of infectious disease: SARS $\quad 522$

NEUGEBAUER, J. T.; see BAXTER, L. H.

NIEMEYER, A. C. and POPIEL, T.; Finding involutions with small support 43

NIKOLAYEVSKY, Y.; see CAIRNS, G.

195

OMIDVAR, M. E.; see SHAH HOSSEINI, M.

PAN, J. M., HUANG, Z. H. and PENG, S. Q.; On arc-regular Frobenius metacirculants

PENG, S. Q.; see PAN, J.

POPIEL, T.; see NIEMEYER, A. C.

PRIYADARSHI, A.; Continuity of the Hausdorff dimension for graph-directed systems

QIAO, S.; see LI, C.

RAHMAN, H.; see BARMAN, R.

RAJAN, P. and WILHELM, F.; Almost nonnegative curvature on some fake 6and 14-dimensional projective spaces

RAMIREZ, J.; see MARQUES, D. 
RAO, G.; Self-complementary vertex-transitive graphs

REPOVŠ, D. and VESNIN, A.; On Gehring-Martin-Tan groups with an elliptic generator

RODTES, K.; Symmetry classes of tensors associated to nonabelian groups of order $p q$

ROSE, M. G.; Expectations over deterministic fractal sets

RYAN, J.; see BAČA, M.

SAIKIA, N.; see BARMAN, R.

SAPIR, O.; see CHEN, Y.

SARIZADEH, A.; A new example of a deterministic chaos game

SAZEEDEH, R.; see AHMADI, K.

SEBAG, J.; see BOURQUI, D.

SEMANIČOVÁ-FEŇOVČÍKOVÁ, A.; see BAČA, M.

SHAH HOSSEINI, M. and OMIDVAR, M. E.; Some inequalities for the numerical radius for Hilbert space operators

SHUMYATSKY, P.; see DE ANDRADE, A. F.

STANFORD, T. E.; Statistical analysis of proteomic mass spectrometry data for the identification of biomarkers and disease diagnosis

STYLOGIANNIS, G.; Semigroups of composition operators on local Dirichlet spaces

SUN, N. K.; The quenching of solutions of a reaction-diffusion equation with free boundaries

SZIKSZAI, M.; see HAJDU, L.

TAM, M. K.; Iterative projection and reflection methods: theory and practice

TANG, M.; A unique representation bi-basis for the integers. II

THABET, F.; On the existence of finite critical trajectories in a family of quadratic differentials

VANDEHEY, J.; Absolutely abnormal and continued fraction normal numbers

VESNIN, A.; see REPOVŠ, D.

WANG, H.-N.; see MA, S.-M.

WANLESS, I. M.; see CAVENAGH, N. J.

WHITE, G. A.; Algorithms for Galois group computations over multivariate function fields

WILHELM, F.; see RAJAN, P.

WORONOWICZ, M.; see ANDRUSZKIEWICZ, R. R.

WU, H.; see LIU, F.

XIA, Q.; On the first eigencone for the Finsler Laplacian

YAMASAKI, Y.; see HIRANO, M.

YANG, Y. L. and ZHANG, D. Y.; The Green-Osher inequality in relative geometry

YI, X.; see LI, C.

YU, H.; On weakly $S$-permutably embedded subgroups of finite groups 
ZENG, M. and ZHOU, G.; A modified FR conjugate gradient method for computing $Z$-eigenpairs of symmetric tensors

ZHANG, D. and ZHAO, H.; The dimension of centralisers of matrices of order $n 353$

ZHANG, D. Y.; see YANG, Y.

ZHANG, Y.; see LIN, L.

479

ZHAO, H.; see ZHANG, D.

353

ZHOU, G.; see ZENG, M.

411 


\section{INFORMATION FOR AUTHORS}

The Bulletin of the Australian Mathematical Society aims at quick publication of original research in all branches of mathematics. To ensure speedy publication, only articles which are sufficiently well presented, able to be published without revision, and which are judged by the Editor (often in consultation with an Associate Editor) to be competitive are refereed. This policy is in the interests of authors, as a quick rejection is better than a slow rejection. The Bulletin receives more than five times the material that can be published, therefore there are many commendable papers not accepted. Editorial decisions on acceptance or otherwise are taken quickly, normally within a month of receipt of the paper. Papers are accepted only after peer review.

Manuscripts are accepted for review with the understanding that the same work is not concurrently submitted elsewhere. For a paper to be acceptable for publication, not only should it contain new and interesting results, but also

(i) the exposition should be clear and attractive, and

(ii) the manuscript should be in publishable form, without revision.

Further information regarding these requirements may be found through our website www.austms.org.au/Bulletin. Authors are asked to avoid, as far as possible, the use of mathematical symbols in the title.

Articles should be prepared in $\mathrm{ET}_{\mathrm{E}} \mathrm{X}$ using $\mathcal{A}_{\mathcal{M}} \mathcal{S}$-LTEX packages and submitted as a PDF file via our journal management system, at www.austms.org.au/Publications/Submissions/BAustMS. This permits authors to track their papers through the editorial process. Recent versions of $\mathrm{T}_{\mathrm{E}} \mathrm{X}$ are able to produce PDF files directly. A LTTEX class file for the Bulletin can be downloaded from the website. Authors who need assistance may email the secretary of the Bulletin at editor@bulletin.austms.org.au.

Authors are advised to keep copies of all files of the submitted article; the Bulletin will not accept responsibility for any loss.

\section{EDITORIAL POLICY}

1. References. Arrange references alphabetically (by surname of the first author) and cite them numerically in the text. Ensure the accuracy of the references: authors' names should appear as in the work quoted. Include in the list of references only those works cited, and avoid citing works which are in preparation or submitted. Where the work cited is not readily accessible (for example, a preprint) a copy of the article should be included with your submission.

\section{Abstracts.}

1. Each paper must include an abstract of not more than 150 words, which should contain a brief but informative summary of the contents of the paper, but no inessential details.

2. The abstract should be self-contained, but may refer to the title.

3. Specific references (by number) to a section, proposition, equation or bibliographical item should be avoided.

3. Subject Classification and Key Words. Authors should include a few key words and phrases and one or more classification numbers, following the American Mathematical Society 2010 Mathematics Subject Classification for all codes. Details of this scheme can be found on the web at www.ams.org/msc.

4. Abstracts of PhD Theses. The Bulletin endeavours to publish abstracts of all accepted Australasian $\mathrm{PhD}$ theses in mathematics. One restriction, however, is that the abstract must be received by the Editor within six months of the degree being approved.

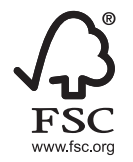

This journal issue has been printed on FSC-certified paper and cover board. FSC is an independent, non-governmental, not-for-profit organisation established to promote the responsible management of the world's forests. Please see www.fsc.org for information. 
The dimension of centralisers of matrices of order $\boldsymbol{n}$

Zhang, D. \&? Zhao, $H$.

Wiener index on traceable and Hamiltonian graphs

Liu, R., Du, X. E Fia, $H$.

Ramanujan Cayley graphs of Frobenius groups

Hirano, M., Katata, K. \& Tamasaki, $Y$.

An upper bound for the number of Diophantine quintuples

Bliznac, M. E Filipin, $A$.

Perfect powers in products of terms of elliptic divisibility sequences

Hajdu, L., Laishram, S. \&̊ Szikszai, $M$.

Deformations of differential arcs

Bourqui, D. E Sebag, 7 .

A modified FR conjugate gradient method for computing $Z$-eigenpairs of symmetric tensors

Zeng, M. \& Zhou, $G$.

Hereditary torsion theories of a locally noetherian Grothendieck category

Ahmadi, K. E Sazeedeh, $R$.

A note on the $\boldsymbol{p}$-supersolubility of finite groups

Li, C., Yi, X. \& Qiao, S.

On weakly $S$-permutably embedded subgroups of finite groups

ru, $H$.

A torsion-free abelian group exists whose quotient group modulo the square subgroup is not a nil-group

Andruszkiereicz, R. R. \& Woronoreicz, $M$.

A note on the Howson property in inverse semigroups

Fones, $P$. $R$.

A new example of a deterministic chaos game

Sarizadeh, $A$.

Continuity of the Hausdorff dimension for graph-directed systems

Priyadarshi, $A$.

The strong irreducibility of a class of Cowen-Douglas operators on Banach spaces

Lin, L. \& Zhang, $Y$.

Some inequalities for the numerical radius for Hilbert space operators

Shah Hosseini, M. \& Omidvar, M. E.

Measures of noncompactness in a Sobolev space and integro-differential equations

Allahyari, R., Arab, R. \& Haghighi, A. S.

Compactness of spaces of convex and simple quadrilaterals

González, A. \& López-López, 7. L.

Abstracts of PhD Theses

A study of spatio-temporal spread of infectious disease: SARS

Naheed, $A$.

Author Index for Volume 94 